\title{
A Relação entre o Conhecimento Conceitual e o Desempenho de Estudantes em Atividades Investigativas
}

\section{The Relationship Between Conceptual Knowledge and Students' Performance in Investigative Activities}

\author{
Rafaela Dinali Nascimento \\ Alessandro Damásio Trani Gomes

Esse trabalho busca identificar a influência do conhecimento conceitual sobre o desempenho de estudantes na execução de uma atividade investigativa, realizada em duplas, por meio de uma simulação computacional. O desempenho dos estudantes foi avaliado segundo um conjunto de fatores: o total de experimentos realizados, a exploração do campo experimental, a percentagem de variáveis independentes pesquisadas; e a quantidade de testes adequados e consistentes realizados. Participaram da pesquisa 160 alunos do primeiro ano do Ensino Médio de uma escola pública federal de Belo Horizonte. Os resultados sugerem que alunos que apresentam um maior conhecimento conceitual sobre o domínio teórico da atividade também apresentam estratégias mais adequadas de controle de variáveis e de experimentação. Com base nos resultados obtidos, são discutidas as implicações educacionais e propostas novas possibilidades de pesquisa na área.

Palavras-chave: Atividades investigativas; conhecimento conceitual; conhecimento procedimental; controle de variáveis.

In this paper, we identify the influence of conceptual knowledge on the performance of students during an investigative activity. The students used a computational simulation, and worked in pairs. Their performance was evaluated according to a set of factors: the number of experiments done, the exploration of the experimental field, the percentage of independent variables surveyed; and the number of adequate and consistent tests performed. A total of 160 first year high school students from a federal public school in Belo Horizonte participated in this study. The results suggest that students who present greater conceptual knowledge about the theoretical domain of the activity also present more adequate strategies of variable control and experimentation. Based on the results, we discuss the educational implications and propose new research possibilities in the area.

Keywords: Investigative activities; conceptual knowledge; procedural knowledge; variable control strategies. 


\section{Introdução}

As diretrizes curriculares vigentes em diversos países, inclusive no Brasil, consideram a Ciência como um corpo de conhecimentos que continuamente se estende, refina e se modifica por meio da análise de evidências, construção e revisão de teorias e modelos. Tais documentos defendem que o ensino de Ciências deva promover a alfabetização científica e a compreensão pública da Ciência, visando o desenvolvimento não somente de conhecimentos amplos e abstratos, mas também de conhecimentos práticos e contextualizados, que contribuam para a formação de uma cultura científica efetiva (NRC, 2012; Osborne, 2014; Rhoton, 2010).

Considerando esta perspectiva para a Educação em Ciências, o laboratório escolar pode se tornar um componente curricular importante para a criação e o desenvolvimento de atividades mais abertas, de natureza investigativa. Segundo várias pesquisas, o planejamento e a execução de investigações podem contribuir para que o estudante estabeleça conexões entre a natureza da Ciência e seus conceitos, bem como entre os procedimentos e as atitudes necessárias para a realização da atividade científica, visando possibilitar não apenas a compreensão conceitual, mas também o seu entendimento sobre os aspectos particulares do fazer científico (Carvalho, 2013; Millar, 2010; Penha, Carvalho, \& Vianna, 2015).

Segundo Borges (2002), as atividades investigativas envolvem a resolução de problemas práticos abertos sobre os quais os estudantes não possuem, de antemão, um roteiro ou uma resposta conhecida por eles, fazendo com que se sintam desafiados a solucioná-los com seus próprios recursos. Nesta perspectiva, os experimentos investigativos

são aqueles que exigem grande participação do aluno durante sua execução. Diferem das outras atividades por envolverem, obrigatoriamente, discussão de ideias, elaboração de hipóteses explicativas e experimentos para testá-las. Nesse sentido, este tipo de atividade estimula, ao máximo, a interatividade intelectual, física e social, contribuindo, sobremaneira, para a formação de conceitos (Bassoli, 2014, p. 583).

A concepção de Ensino de Ciências por Investigação adotada neste trabalho é coerente com a de autores que recomendam a utilização de diversas abordagens de ensino que estimulem o raciocínio por meio da experimentação e do processo de resolução de problemas (Deboer, 2006; NRC, 2000). Para que os alunos realizem satisfatoriamente uma atividade investigativa é necessário a mobilização de uma série de competências e habilidades relacionadas à experimentação como: identificar questões e problemas a serem resolvidos; formular hipóteses; propor procedimentos de coleta e análise dos dados; relacionar grandezas e parâmetros relevantes; construir explicações utilizando modelos físicos e os dados disponíveis; comunicar os resultados obtidos; dentre outras (Pedastre et al., 2015; MEC, 1999).

A realização de uma investigação requer que o estudante articule, de forma harmoniosa, habilidades cognitivas e conhecimentos procedimentais e conceituais, 
desenvolvendo-os e integrando-os simultaneamente. Para Gott e Roberts (2008), o conhecimento conceitual se refere à compreensão das principais ideias, teorias, conceitos e leis da Ciência, enquanto o conhecimento procedimental diz respeito ao domínio de uma série de técnicas práticas e habilidades manipulativas, relacionadas com o 'saber como’ da Ciência e com o conhecimento necessário para se pôr a Ciência em prática.

Dentre as habilidades e processos que caracterizam o conhecimento procedimental do indivíduo na realização de atividades investigativas, destaca-se a capacidade de realizar testes experimentais adequados e consistentes. Um teste adequado e consistente é aquele que toma as variáveis propostas numa situação-problema e as manipula de maneira similar ao que a literatura denomina estratégia de controle de variáveis. $\mathrm{O}$ teste é adequado se a variável cujo efeito se deseja determinar é tomada como variável independente. O teste é consistente se apenas essa variável se modifica entre duas ou mais repetições experimentais, sendo que todas as outras variáveis são mantidas inalteradas (Schwichow et al., 2016).

Neste trabalho, partimos da hipótese de que cada estudante faz uso de seu conhecimento conceitual para compreender a atividade e para representar as relações entre as variáveis envolvidas no problema. Isso pode explicar a diversidade de estratégias de investigação adotada e contribuir para um maior entendimento sobre essa diversidade e a influência das diferenças pessoais no desempenho durante a realização da atividade. Além disso, defendemos, assim como Millar e Driver, que

o processo da experimentação depende do conhecimento prévio do estudante. A maneira como ele conduz o experimento, os fatores que são selecionados para a investigação e aqueles que são controlados não são características objetivas, mas decorrem da representação mental que o estudante tem da atividade em questão (Millar, \& Driver, 1987, p. 50).

Embora o envolvimento dos estudantes em atividades investigativas seja ressaltado enfaticamente por educadores como fundamental para a aprendizagem sobre a natureza da Ciência e sobre o processo de investigação científica, pesquisas na área da Psicologia e Cognição apontam que, quando engajados em investigações, indivíduos de todas as idades, enfrentam certas dificuldades características (Dunbar, \& Klahr, 2012; Morris et al., 2012). Por isso, há a necessidade de análises mais aprofundadas dos fatores que influenciam a execução de investigações, assim como o desenvolvimento de metodologias específicas que permitam relacionar o conhecimento conceitual do aluno com suas ações durante a atividade. Nesse sentido, esse trabalho tem como objetivo identificar a influência do conhecimento conceitual sobre o desempenho do estudante na realização de uma atividade investigativa. 


\section{Relação entre o conhecimento conceitual e processos relacionados à experimentação}

Wellman e Gelman (1992) afirmam que muito antes de entrar na escola, crianças distinguem o mundo físico, o mundo natural e o mundo mental, e começam a raciocinar de forma bastante diferente nesses três domínios. Segundo os autores, as crianças (a) reconhecem e fazem distinções ontológicas, (b) utilizam princípios causais para raciocinar em domínios específicos, e (c) possuem uma rede coerente de relações causais que interliga vários conceitos em um mesmo domínio. Portanto, a pesquisa sobre a caracterização das estruturas cognitivas e conceituais específicas de cada área do conhecimento se torna fundamental, em vista do papel que elas desempenham na aprendizagem de novos conhecimentos.

Boa parte das pesquisas que ocorreram ao longo da década de 80 e 90 na área de Educação em Ciências se dirigiu a identificar, investigar e descrever os conceitos e ideias que os indivíduos possuem sobre os mais diversos fenômenos naturais, nas mais variadas áreas da Ciência. Um dos principais focos dessas pesquisas são as ideias ou conceitos intuitivos que as pessoas, mesmo crianças, trazem para a sala de aula. Tais ideias, geralmente distantes dos conceitos científicos, são construídas, desde a infância, por meio da interação com o meio físico, cultural e social. A produção desse período é bem conhecida e foi sumarizada em amplas revisões (Driver et al., 1994; Wandersse, Mintzes, \& Novak, 1994). Além disso, as pesquisas na área de mudança conceitual (Carey, 2000; Chi, 2008; Kang, Scharmann, \& Noh, 2004) e de modelos mentais (Frederiksen, White, \& Gutwill, 1999; Gilbert, \& Boulter, 2000) contribuíram para chamar atenção para a importância das concepções e modelos prévios para os estudantes ao defenderem, por exemplo, que:

essas supostas teorias intuitivas têm as mesmas funções explicativas e preditivas para as crianças que as teorias formais têm para os cientistas, permitindo a crianças e cientistas não apenas observar e descrever fenômenos, mas também fornecer explicações e previsões (Amsel, \& Brock, 1996, p. 524).

Trabalhos realizados a partir da década de 90 começaram a investigar o desempenho dos indivíduos na realização de tarefas e na resolução de problemas práticos, nos quais seus conhecimentos conceituais específicos impõem certos vieses e tendências. Um dos objetivos seria a compreensão do pensamento das pessoas em situações e atividades nas quais seus conhecimentos específicos e gerais guiam a forma como os procedimentos experimentais são definidos e como os resultados e evidências são analisados.

Alexander e Judy (1988) levantam algumas hipóteses sobre a interação do conhecimento conceitual específico e do conhecimento geral tido, por muitos, como um conhecimento estratégico e procedimental. Segundo as autoras:

- certo grau de conhecimento específico é necessário para a utilização efetiva e eficiente dos conhecimentos procedimentais; 
- um conhecimento específico incompleto ou inadequado sobre o domínio teórico pode inibir, interferir ou atrapalhar a aplicação de conhecimentos procedimentais, prejudicando a aprendizagem;

- a importância relativa exercida pelo conhecimento específico e pelo conhecimento estratégico durante a realização de uma tarefa qualquer pode ser consequência da natureza e da estrutura da atividade.

Considerando essas ideias, vários autores passaram a investigar como o conhecimento conceitual de crianças e adolescentes interage com os processos cognitivos mobilizados por eles durante atividades desenvolvidas em contextos ricos em concepções espontâneas como, por exemplo, o afundamento dos corpos em líquidos (Gonçalves, \& Carvalho, 1994; Penner, \& Klahr, 1996; Sasseron, \& Carvalho, 2003). De uma forma geral, indivíduos possuem certo conhecimento intuitivo sobre esse domínio teórico, fruto do cotidiano. Porém, o conhecimento físico adequado para analisar o problema de afundamento dos corpos não é simples, pois envolve questões como atrito viscoso, empuxo etc. Além disso, devido a alguns fatores estarem correlacionados, como, por exemplo, o tamanho do objeto, sua densidade e seu peso, o processo de isolar e controlar as variáveis torna-se mais complicado, dificultando a obtenção de evidências válidas.

Penner e Klahr (1996), por exemplo, perceberam que as crianças não demonstraram dificuldade em entender o problema proposto (identificar os fatores que influenciam no tempo de afundamento dos corpos). Porém, poucas realizaram mais do que os quatro experimentos exigidos na atividade, mesmo sendo livres para realizar quantos desejassem e tendo sido apresentados, previamente a todos os 28 pares possíveis de combinações de variáreis. Consequentemente, os participantes obtiveram bem menos informações na fase de experimentação do que era possível. Mesmo assim, todos aprenderam, por meio da experimentação, sobre a influência de outras variáveis que compunham o problema, pois a maioria acreditava que apenas a massa do objeto era relevante. Os autores concluíram que o conhecimento prévio dos indivíduos influencia no objetivo inicial do processo de experimentação e que as crianças mais velhas têm uma tendência maior a ver o processo de experimentação como forma de testar hipóteses e de utilizar mais frequentemente testes adequados e consistentes. Por outro lado, as crianças mais novas realizam experimentos sem uma hipótese definida ou como uma forma de confirmar seus conhecimentos.

Schauble (1990) procura descrever as mudanças no conhecimento e nas estratégias de crianças quando estas trabalham com atividades investigativas ao longo de um período extenso de tempo. Seu objetivo maior é o de observar as estratégias que elas utilizam para gerar e analisar as evidências obtidas, procurando identificar situações nas quais o conhecimento prévio da criança poderia influenciar nesses processos. Segundo a autora, elas raramente fizeram uso de anotações para registrar os passos tomados ou os resultados parciais de cada experimento, recorrendo à sua memória durante as oito semanas de coleta de dados. Cada participante executou uma média de 23 experimentos. Das 48 combinações entre as variáveis possíveis, as crianças utilizaram, em média, pouco 
mais da metade, além de, com certa frequência, repetirem configurações experimentais já utilizadas, o que caracteriza uma investigação idiossincrática e/ou pouco sistemática. De forma geral, as estratégias utilizadas pelas crianças evoluíram ao longo da atividade, mas heurísticas como a tendência a confirmar os conhecimentos e a maior preocupação com as variáveis tidas como causais, exploradas em trabalhos anteriores, também foram identificadas entre os participantes (Klayman, \& Ha, 1987). Isso prejudicou o desenvolvimento de uma estratégia experimental mais sofisticada, a avaliação dos resultados obtidos e a revisão das concepções prévias de parte do grupo analisado.

Neste trabalho, utilizamos o termo estratégia para designar uma série de procedimentos e/ou processos cognitivos orientados para um objetivo, que são intencionalmente utilizados durante a realização da atividade. Para Alexander e Judy (1988), o saber condicional ou estratégico é uma forma especial de conhecimento procedimental eengloba o entendimento de como coordenar as informações eos processos cognitivos para determinar quando e onde aplicar determinados procedimentos. Para Roberts e Newton (2001), estratégia pode ser vista como um conjunto de processos cognitivos que podem ser estimulados, modificados e sofisticados. Cada indivíduo dispõe, portanto, de um repertório limitado de estratégias, cuja riqueza e diversidade dependem da história e experiências de aprendizagem já vividas. Inclusive, para alguns autores, o desenvolvimento do indivíduo ocorre justamente na mudança do modo como ele seleciona determinada estratégia para a utilização e de como novas são adquiridas (Sophian, 1997).

No contexto brasileiro, Borges, Borges e Vaz (2005) avaliam as estratégias utilizadas para identificação e controle das variáveis em planos de investigação de estudantes de $3^{\circ}$ ano do Ensino Médio, elaborados com o objetivo de identificar quais fatores afetam a duração de dois eventos distintos. Como resultado da análise, os autores verificaram, de forma geral, a pouca quantidade de bons planos. Eles concluíram que a qualidade dos planos desenvolvidos para testar as hipóteses depende do desempenho escolar em Física, embora essa relação não seja simples, e que uma fração de bons planos depende fortemente da natureza do problema.

De forma geral, os trabalhos sobre o pensamento científico e as habilidades relativas ao processo de investigação indicam que há uma grande relação entre as estratégias utilizadas no planejamento e na execução das atividades e as hipóteses que indivíduos formulam. Isto sugere que as estratégias empregadas refletem os diferentes níveis de compreensão, tanto conceitual quanto procedimental, e que o conhecimento prévio afeta de forma decisiva essas estratégias, tendo um forte impacto sobre o teste de hipóteses (experimentação) e sobre a interpretação dos resultados (Dunbar, \& Klahr, 2012; Zimmerman, 2007). Koslowski (1996) afirma que os indivíduos, ao longo de suas interações com o mundo físico, mesmo não possuindo um conhecimento conceitual específico, adquirem um 'senso de mecanismo', uma ideia ou noção de como e por que as coisas funcionam. Para Schauble,

indivíduos tendem a desenvolver mecanismos e modelos que expliquem os fenômenos 
que eles observam; os fenômenos observados têm um importante papel nos tipos de mecanismos que são utilizados, e os mecanismos, por sua vez, determinam a forma como os dados são analisados e interpretados (Schauble, 1996, p.117).

Portanto, quando indivíduos realizam atividades investigativas, seus conhecimentos anteriores, suas crenças e seus valores impõem, de algum modo, certos limites e vieses teóricos, tendo influência marcante na maneira como eles formulam hipóteses, na seleção de estratégias experimentais para coletar os dados e na avaliação das evidências.

As pesquisas revelam, ainda, uma tendência das pessoas em geral, e estudantes em particular, de verem a experimentação apenas como forma de comprovar seus conhecimentos e suas hipóteses iniciais. Isso explica porque, muitas vezes, eles desconsideram os resultados obtidos e mantêm firmes suas convicções. Além disso, indivíduos têm a tendência de focar mais sua atenção em variáveis que julgam previamente causais do que naquelas avaliadas como não causais (Croker, \& Buchanan, 2011; Tschirgi, 1980).

O diálogo entre educadores, psicólogos e pesquisadores na área de cognição humana aumentou na última década (Faria, \& Vaz, 2014; Zimmerman, 2007). Apesar disso, a pesquisa de Educação em Ciências ainda carece de informações sobre o pensamento científico dos estudantes, o domínio acerca dos processos envolvidos e quais fatores influenciam suas ações durante a resolução de um problema prático, sobretudo quando implementado em situações reais de ensino. Porém, a pesquisa na área traz alguns desafios.

Dada a interdependência e a relação das habilidades e estratégias envolvidas durante a investigação e os conhecimentos prévios dos indivíduos, é impossível dissociálos ou examiná-los de forma independente, o que vinha sendo tentado em pesquisas anteriores (consultar Gomes, Borges, \& Justi (2008b) para uma revisão). Apesar das limitações, essas pesquisas (Amsel, \& Brock, 1996; Kuhn, Amsel, \& O’loughlin, 1988; Sodian, Zaitchik, \& Carey, 1991; Tschirgi, 1980, por exemplo) geraram um grande volume de conhecimento e informações sobre o desenvolvimento do pensamento científico dos indivíduos e o processo de investigação. Porém, esses trabalhos não abordaram a interação entre os processos de geração de hipóteses, teste via experimentação e análise de evidências. Nas palavras de Klahr,

[...] essa interação pode ser bastante complexa; consequentemente, na maioria dos estudos sobre o pensamento científico, a metodologia de pesquisa consistiu em investigar cada habilidade isoladamente e em contextos semanticamente limpos. Essa estratégia obteve resultados muito importantes sobre as diferentes etapas do processo científico, mas ainda resta muito para ser compreendido sobre como essas etapas interagem entre si e como essa interação é influenciada pelo conhecimento prévio do indivíduo (Klahr, 2000, p. 59).

Em nosso trabalho, não consideramos apenas o resultado, mas tentamos caracterizar o raciocínio dos estudantes durante toda a atividade investigativa, buscando 
responder às seguintes questões de pesquisa:

- Como se manifesta a influência do conhecimento conceitual do estudante sobre o seu desempenho durante a realização de uma atividade investigativa?

- Como as estratégias experimentais utilizadas pelos estudantes permitem relacionar o seu conhecimento conceitual com o desempenho na realização da investigação?

A atividade investigativa analisada neste trabalho foi desenvolvida por meio de uma simulação computacional e o desempenho na investigação pôde ser avaliado por vários fatores em conjunto: o número de experimentos realizados, a exploração do campo experimental, a quantidade de variáveis independentes pesquisadas; e a quantidade de testes adequados e consistentes realizados.

\section{Aspectos metodológicos}

\section{Sujeitos da pesquisa}

Participaram da pesquisa 160 alunos de sete turmas do primeiro ano do Ensino Médio de uma escola pública federal de Belo Horizonte, com idades variando entre 14,9 e 18,3 anos e média de 16,2 anos. Nessa escola, o currículo de Física tem um forte caráter experimental aproveitando-se da estrutura de laboratórios e de outros recursos disponíveis. Os alunos da escola realizam atividades práticas semanalmente.

Para que estes alunos pudessem participar das atividades de coleta de dados, uma carta foi enviada aos pais e/ou responsáveis explicando detalhadamente os objetivos gerais da pesquisa, o que os alunos fariam e ressaltando a garantia da integridade física e moral do participante, deixando claro que não se tratava de uma atividade escolar e que, portanto, a participação do aluno era voluntária e não obrigatória.

\section{Instrumentos e procedimentos da pesquisa}

As características dos instrumentos de pesquisa e da metodologia desenvolvida obedecem ao paradigma recente das pesquisas na área da cognição e do desenvolvimento do pensamento científico (Klahr, Zimmerman, \& Jirout, 2011; Kuhn, 2016; Morris et al. 2012;) e se fundamentam na identificação das atividades propostas com a atividade científica real, na qual:

- o conhecimento prévio do domínio teórico deve influenciar a forma, o conteúdo, a estrutura e a especificidade das hipóteses formuladas;

- o contexto da atividade deve ser suficientemente complexo para permitir uma diversidade de hipóteses e um vasto campo de experimentação, para que as buscas nos respectivos campos não sejam triviais;

- os participantes devem planejar e executar seus próprios experimentos; 
- os participantes não devem apenas trabalhar com padrões de covariação ou conjunto de dados pré-determinados, mas sim, produzi-los para que possam ser analisados de acordo com as hipóteses iniciais;

- os participantes devem ter a liberdade de decidir quando parar. Eles devem basear suas conclusões na análise das evidências obtidas, rever as hipóteses iniciais e decidir se os objetivos propostos para a atividade foram alcançados.

A resolução de uma atividade investigativa envolve a interação entre os conhecimentos conceituais e procedimentais. Procuramos, portanto, identificar os conhecimentos conceituais dos alunos para, em seguida, explorarmos a influência desse conhecimento sobre o seu desempenho na atividade. Para uma maior organização, os instrumentos da pesquisa serão descritos separadamente, na ordem de apresentação aos alunos.

\section{Levantamento do conhecimento conceitual dos participantes}

Para identificar o conhecimento conceitual dos estudantes, foi solicitado que eles respondessem a dois questionários contento questões discursivas e de múltipla escolha sobre os temas das investigações (Figuras 1 e 2). Um questionário versou sobre equilíbrio térmico e termologia, enquanto o outro abordou o movimento acelerado e plano inclinado. Os questionários são compostos por oito questões cada um, algumas delas elaboradas para a pesquisa, outras originadas ou adaptadas de livros de Física ou provas de ingresso em universidades.

Também foram obtidas, com a autorização da direção da escola, junto aos quatro professores das turmas do primeiro ano do Ensino Médio, as notas dos alunos referentes às três provas trimestrais realizadas no ano. As notas das provas trimestrais também foram utilizadas como indicativo do conhecimento conceitual dos alunos em Física, pois essas provas eram as mesmas para todos os alunos e eram elaboradas e corrigidas por uma mesma equipe de professores. 
1) Defina o que você entende por calor e o que você entende por temperatura. Em seguida, relacione essas duas grandezas físicas.

2) Quando uma enfermeira coloca um termômetro clínico de mercúrio sob a língua de um paciente, ela sempre aguarda algum tempo antes de fazer a leitura. Esse intervalo de tempo é necessário:

a) para que o termômetro entre em equilíbrio térmico com o corpo do paciente.

b) para que o mercúrio, que é muito pesado, possa subir pelo tubo capilar.

c) para que o termômetro retenha o calor do corpo da pessoa.

d) por causa da diferença entre os valores do calor específico do mercúrio e o corpo humano.

3) Quando dois corpos, de materiais diferentes e massas iguais, estão em equilíbrio térmico, podemos afirmar que:

a) ambos possuem a mesma capacidade térmica.

b) ambos possuem a mesma temperatura.

c) ambos possuem a mesma variação térmica.

d) ambos possuem a mesma quantidade de calor.

4) Um cano de cobre e um de alumínio, ambos de mesma massa, recebem a mesma quantidade de calor. Observa-se que o aumento de temperatura do cano de alumínio é menor que o do cano de cobre.

Isso acontece porque o alumínio:

a) tem calor específico maior que o do cobre.

b) tem calor específico menor que o do cobre.

c) é melhor condutor de calor que o cobre.

d) é pior condutor de calor que o cobre.

5) Dois blocos de chumbo $P$ e $Q$ sofrem ambos a mesma variação de temperatura

$\Delta t=50^{\circ} \mathrm{C}$ ao serem aquecidos. A massa do bloco P é o dobro da massa do bloco $Q$. Sendo assim, a quantidade de calor absorvido pelo bloco $Q$ é: a) maior que a quantidade de calor absorvida por P.

b) menor que a quantidade de calor absorvida por $P$.

c) igual à quantidade de calor absorvida por $\mathrm{P}$.

d) impossível de determinar.

6) Um recipiente isolado termicamente, contém um litro de água a uma temperatura inicial $\mathrm{T}$. Adicionando-se a este sistema um litro de água a uma temperatura $2 \mathrm{~T}$, a temperatura final após estabelecido o equilíbrio térmico será?
a) $\mathrm{T}$
b) Menor que $T$
c) Algum valor entre $\mathrm{T}$ e $2 \mathrm{~T}$
d) Maior que 2T

7) Dois corpos $A$ e $B$, inicialmente às temperaturas $\mathrm{TA}=90^{\circ} \mathrm{C}$ e $\mathrm{TB}=20^{\circ} \mathrm{C}$, são postos em contato e isolados termicamente do meio ambiente. Eles atingem o equilíbrio térmico à temperatura de $45^{\circ} \mathrm{C}$. Nestas condições, podemos afirmar que o corpo A:

a) cedeu uma quantidade de calor maior do que a absorvida por B;

b) cedeu uma quantidade de calor igual à absorvida por B;

c) teve sua quantidade de calor armazenada reduzida pela metade;

d) não sofreu alteração na sua quantidade de calor armazenada;

8) Deseja-se aquecer uma certa massa de água até uma determinada temperatura. Para isso, utiliza-se um ebulidor que fornece uma quantidade determinada e constante de calor por unidade de tempo. Supondo que, utilizandose esse ebulidor, aqueça-se 1 litro de água em 4 minutos, quantos minutos serão necessários para se aquecer 2 litros de água até a mesma temperatura?
a) 2
b) 8
c) 4
d) impossível de determinar.

Figura 1. Questionário para identificação do conhecimento conceitual - Equilíbrio térmico 
1) $O$ que você entende por um movimento acelerado?

2) Considere uma bolinha se movimentando conforme as figuras abaixo. Em cada caso, estão representados os vetores velocidade e aceleração. Associe o desenho à descrição do tipo de movimento:

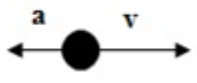

(I)

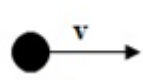

(II)

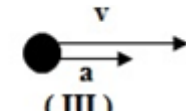

(III)
Movimento Uniforme;

Movimento Uniformemente Acelerado; Movimento Uniformemente Retardado;

3) Marque U para a situação na qual o movimento descrito é um exemplo de movimento retilíneo uniforme, UA, se o exemplo for de movimento retilíneo uniformemente acelerado e UR se a situação exemplificar um movimento retilíneo uniformemente retardado (Despreze a resistência do ar).

Uma bola lançada verticalmente para cima até atingir o ponto máximo;

Uma bola descendo uma rampa inclinada sem atrito;

A bola de boliche durante seu movimento antes da colisão com os pinos;

Um carro em alta velocidade, parando em um sinal vermelho;

4) Um carro desce por uma rua inclinada, continua movendo-se por uma rua horizontal e, em seguida, colide com um poste. Ao investigar 0 acidente, um perito de trânsito verificou que o carro tinha um vazamento de óleo que fazia pingar no chão gotas em intervalos de tempo iguais. Ele verificou também que a distância entre as gotas era constante na rua inclinada e diminuía gradativamente na rua horizontal. Desprezando a resistência do ar, o perito pode concluir que o carro:

a) vinha acelerando na descida e passou a frear na rua plana.

b) descia com velocidade constante a rua inclinada e passou a frear na rua plana.

c) vinha freando desde o trecho no plano inclinado.

d) não reduziu a velocidade até o choque.
5) Considere uma esfera descendo uma rampa inclinada. Assinale a alternativa falsa.

a) O coeficiente de atrito dependerá apenas dos materiais da esfera e da rampa.

b) A aceleração da esfera aumenta a medida que a esfera desce a rampa.

c) Se aumentarmos a inclinação da rampa, a velocidade final da esfera será maior.

d) A cada segundo, a velocidade da esfera aumenta sempre de um mesmo valor.

6) Suponha que tenhamos um carrinho descendo uma rampa sem atrito. Fixado a ele, há um marcador que deixa marcas sobre a rampa em intervalos iguais de tempo.

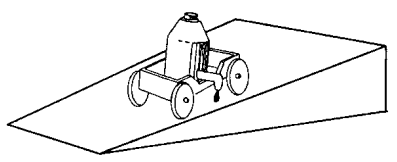

Qual das figuras abaixo, melhor representa as marcas deixadas por esse carrinho ao descer a rampa?
a. $\quad \cdot+\cdot$

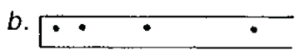
c. $\bullet$
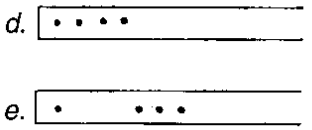

Os enunciados das questões 7 e 8 referem-se ao movimento de uma bola abandonada em um plano inclinado no instante $\mathrm{t}=0 \mathrm{~s}$.
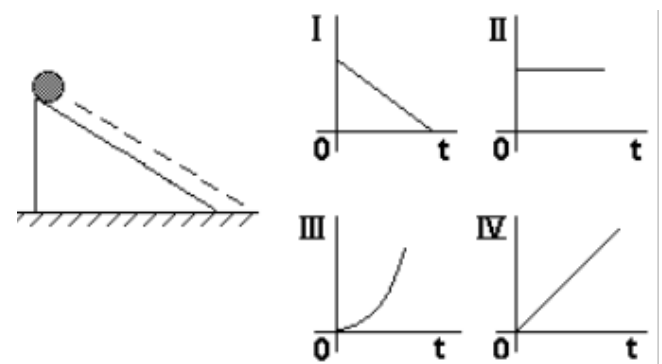

7) $O$ gráfico que melhor representa a distância percorrida pela bola durante o movimento é:
a) I
b) II
c) III
d) IV

8) O gráfico que melhor representa o módulo da velocidade da bola durante o movimento é:
a) I
b) II
c) III
d) IV

Figura 2. Questionário para identificação do conhecimento conceitual - Plano inclinado 


\section{Atividades investigativas}

A realização das atividades investigativas ocorreu por meio de simulações computacionais. A preferência por simulações aos experimentos didáticos comumente utilizados se deu pela maior rapidez e facilidade em coletar os dados. A realização de uma atividade experimental tradicional demandaria a análise de uma quantidade enorme de material e um tempo excessivo para coletar os dados, o que inviabilizaria a pesquisa.

As simulações utilizadas, especialmente desenvolvidas para a pesquisa, contemplam boa parte das caraterísticas de uma investigação identificadas por Pedastre et al. (2015), permitindo a geração de hipóteses, a previsão de resultados experimentais, a manipulação livre das variáveis envolvidas, a interpretação dos resultados e a formulação de conclusões a respeito do problema abordado, além das características elencadas no início da seção.

De interface amigável, desenvolvidas sob plataforma Windows, as simulações se mostraram facilmente entendidas e utilizadas pelos participantes da pesquisa. As telas principais de cada uma delas são apresentadas nas figuras 3 e 4 . Os estudantes tinham aulas semanais da disciplina Informática, e, por isso, o manuseio do computador em si não ofereceu dificuldade específica para eles.

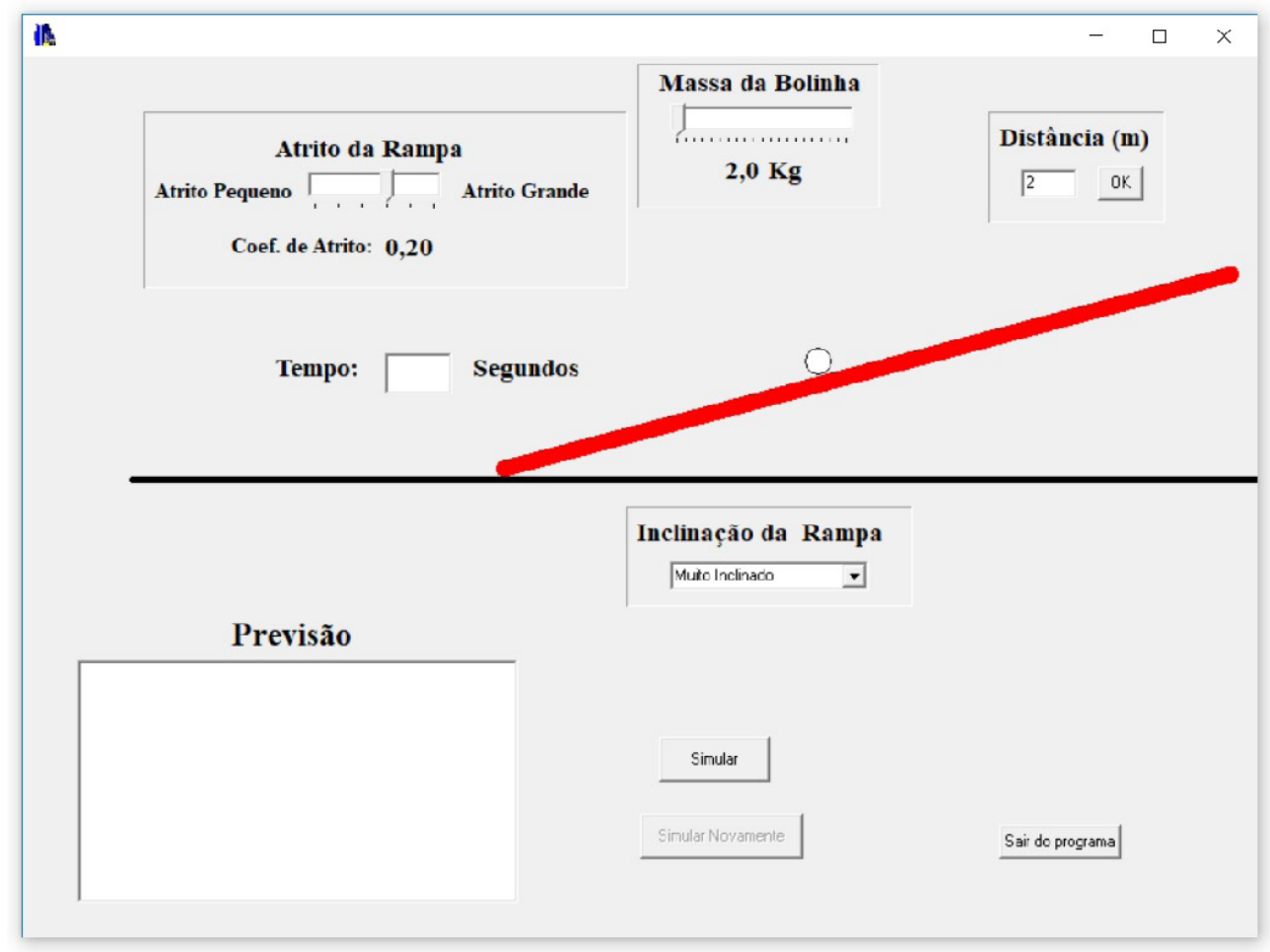

Figura 3. Tela principal da simulação para o problema do plano inclinado

Foram desenvolvidas simulações que abordaram dois temas (termologia/ equilíbrio térmico e movimento acelerado/plano inclinado), mas com configurações experimentais semelhantes. O objetivo de cada investigação foi o de estabelecer quais variáveis, em um conjunto de variáveis independentes, exerciam influência sobre uma 
determinada variável dependente.

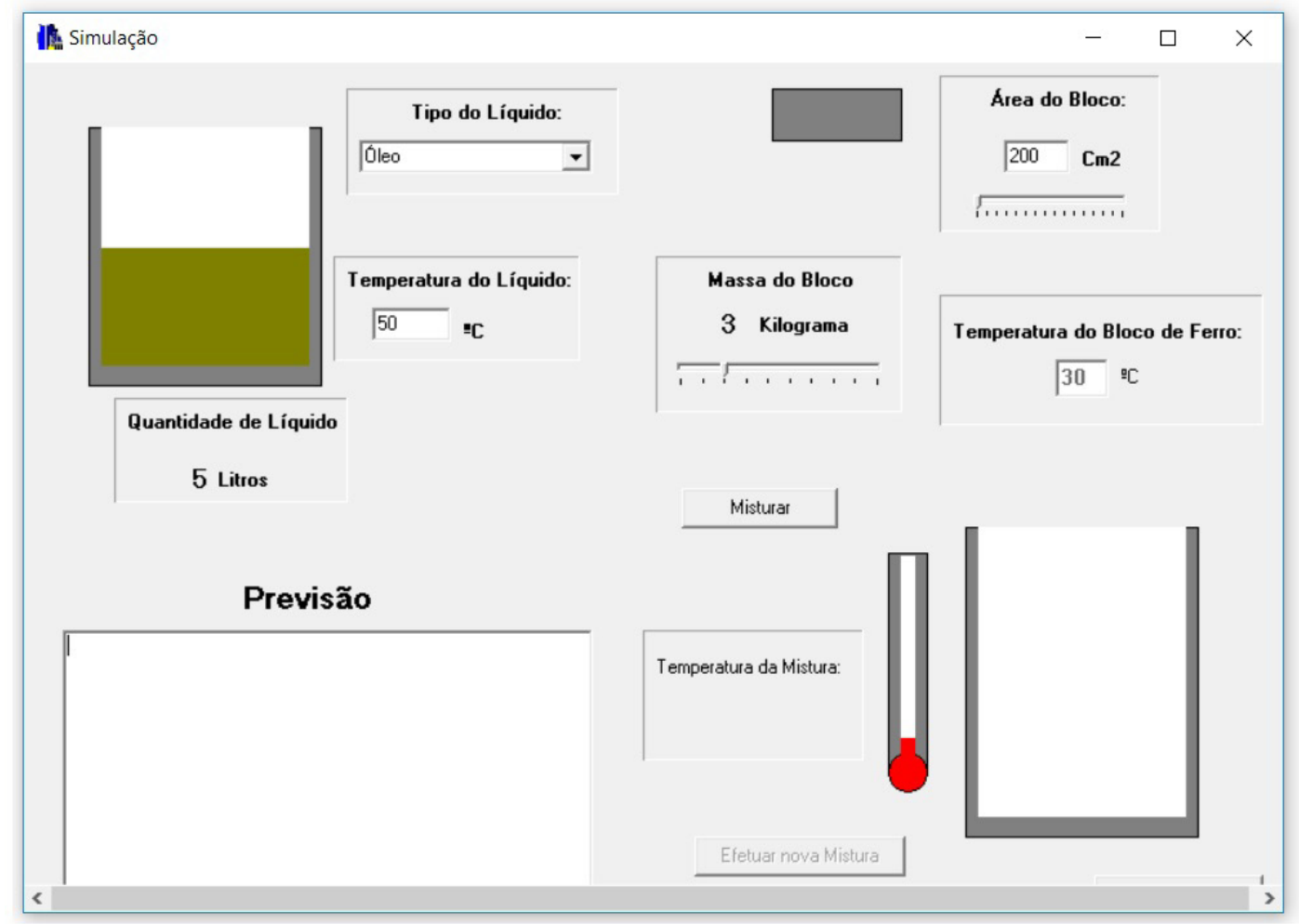

Figura 4. Tela principal da simulação para o problema do equilíbrio térmico

Dentre as variáveis independentes, havia aquelas causais (que influenciam na variável dependente) e uma, não causal (que não tem influência sobre a variável dependente). A Figura 5 apresenta as principais características das atividades investigativas desenvolvidas.

Como evidenciado na Figura 5, para cada um dos dois temas escolhidos foram desenvolvidas duas simulações que apresentavam como diferença básica o número de variáveis independentes envolvidas. Para as atividades investigativas que envolviam apenas duas variáveis, as demais eram tomadas como fatores constantes.

As investigações, por meio das simulações computacionais, foram realizadas em duplas. Essa opção foi feita tentando aproximar o ambiente da pesquisa ao de um laboratório escolar, no qual o estudante raramente trabalha sozinho. Além disso, o trabalho em dupla estimula a troca de ideias e estratégias, havendo indícios que indicam que a performance de dois estudantes trabalhando juntos é frequentemente superior ao trabalho individual de cada um (Kaselman, 2003; Roth, 1995).

As atividades investigativas utilizadas nesse estudo foram concebidas para promover a oportunidade de observar as estratégias de geração de evidências que os alunos utilizam em um contexto cujo conhecimento de senso comum e o 'senso de mecanismo’ são muito fortes. Além disso, elas propiciam também analisar como essas estratégias evoluem ou se modificam ao longo do tempo. Dessa forma, as investigações propostas demandam dos estudantes a coordenação da busca tanto no espaço dos 
experimentos quanto no espaço das hipóteses, assim como a avaliação das evidências produzidas durante a experimentação (Dunbar, \& Klahr, 2012).

\begin{tabular}{|c|c|c|c|c|}
\hline Tema & Objetivo & $\begin{array}{c}\text { Variáveis } \\
\text { Independentes }\end{array}$ & Fatores/Variáveis & Tipo de variáveis \\
\hline \multirow[b]{2}{*}{$\begin{array}{l}\text { Equilíbrio } \\
\text { térmico }\end{array}$} & \multirow[b]{2}{*}{$\begin{array}{l}\text { Determinar } \\
\text { quais fatores } \\
\text { influenciam na } \\
\text { temperatura } \\
\text { final do } \\
\text { sistema }\end{array}$} & 2 & $\begin{array}{l}\text { Área superf. do bloco } \\
\text { Temperatura do } \\
\text { líquido }\end{array}$ & $\begin{array}{l}\text { Discreta (20 níveis) } \\
\text { Contínua }\end{array}$ \\
\hline & & 4 & $\begin{array}{l}\text { Área superf. do } \\
\text { bloco } \\
\text { Temperatura do } \\
\text { líquido } \\
\text { Tipo do líquido } \\
\text { Massa do bloco }\end{array}$ & $\begin{array}{l}\text { Discreta (20 níveis) } \\
\text { Contínua } \\
\text { Nominal ( } 3 \text { níveis) } \\
\text { Discreta (10 níveis) }\end{array}$ \\
\hline \multirow[b]{2}{*}{$\begin{array}{l}\text { Plano } \\
\text { inclinado }\end{array}$} & \multirow{2}{*}{$\begin{array}{l}\text { Determinar } \\
\text { quais fatores } \\
\text { influenciam o } \\
\text { tempo que as } \\
\text { esferas gastam } \\
\text { para percorrer } \\
\text { a rampa }\end{array}$} & 2 & $\begin{array}{l}\text { Distância } \\
\text { Massa da esfera }\end{array}$ & $\begin{array}{l}\text { Contínua } \\
\text { Discreta (20 níveis) } \\
\end{array}$ \\
\hline & & 4 & $\begin{array}{l}\text { Distância } \\
\text { Massa da esfera } \\
\text { Inclinação } \\
\text { Atrito }\end{array}$ & $\begin{array}{l}\text { Contínua } \\
\text { Discreta (20 níveis) } \\
\text { Nominal (3 níveis) } \\
\text { Discreta (6 níveis) }\end{array}$ \\
\hline
\end{tabular}

Figura 5. Características das atividades investigativas

Durante toda a coleta de dados, os estudantes preencheram os valores das variáveis independentes, justificando, em um espaço apropriado, os valores determinados. Em seguida, ao clique de um botão, o resultado era fornecido, com uma breve animação, e era solicitado um comentário sobre o resultado obtido. Ao finalizar o comentário, a dupla tinha a opção de continuar com a investigação ou sair do programa. Ao sair, todas as informações eram gravadas e armazenadas em um arquivo de extensão 'txt', que permanecia disponível para análise. Esses arquivos, com o histórico da investigação realizada por cada dupla, foram a principal fonte de dados analisados neste estudo.

A realização das atividades da pesquisa ocorreu no início do segundo semestre letivo, durante o horário normal de aula. Cada turma realizou as atividades da pesquisa em duas aulas de 100 minutos cada, uma para cada investigação. A ordem do tema da investigação variou de turma para turma. Portanto, os alunos de determinadas turmas realizaram as atividades relativas ao tema 'equilíbrio térmico' na primeira aula e as atividades do tema 'plano inclinado' na outra, mantendo-se as mesmas duplas. Para outras turmas, ocorreu o inverso. Em quaisquer dos casos, antes da realização da investigação, os estudantes responderam, individualmente, o respectivo questionário para identificação do conhecimento conceitual sobre o domínio teórico da atividade.

Para este trabalho, são considerados apenas os dados da primeira atividade realizada em cada turma. Pesquisas apontam que, mesmo na ausência de instruções 
explícitas, quando são fornecidas oportunidades aos estudantes de praticar atividades investigativas, há uma melhoria, apesar de limitada, no seu desempenho. Essa melhoria é medida, sobretudo, em relação à capacidade de executar testes experimentais adequados e consistentes e à ampliação da exploração do campo experimental (Klahr, \& Toth, 1999; Ross, 1988).

\section{Tratamento inicial, refinamento e análise preliminar dos dados}

Considerando as questões de pesquisa e para melhor compreensão do trabalho realizado, apresentamos a seguir como os dados coletados foram tratados e preparados para as análises apresentadas na próxima seção.

\section{Levantamento do conhecimento conceitual dos participantes}

Para identificação do conhecimento conceitual foram realizados os processos de correção e de atribuição de notas às respostas dos estudantes nos questionários. As questões de múltipla escolha foram corrigidas de forma dicotômica, sendo atribuído o valor de um ponto caso respondente acertasse a questão e zero, em caso de erro. As questões abertas foram corrigidas por dois pesquisadores, seguindo critérios bem definidos. Houve uma percentagem de concordância de 95\%. Os casos de divergência foram resolvidos por consenso entre os corretores. Após esse processo, houve a conversão da nota da questão para a escala de 0 a 1 . Dessa forma, as notas dos estudantes variaram entre 0 e 8 pontos.

Os questionários foram submetidos a processos de validação de conteúdo e preditiva. Os coeficientes alfa de Cronbach e beta de Silveira também foram calculados. Os valores obtidos atestam positivamente sobre a consistência interna e a fidedignidade dos questionários elaborados (Silveira, 1993). Uma descrição detalhada sobre os processos de correção e validação, bem como a análise mais aprofundada dos resultados dos questionários podem ser obtidos em Nascimento e Gomes (2017). Os dados estatísticos relevantes referentes aos questionários estão na Tabela 1.

Tabela 1. Principais dados estatísticos dos questionários

\begin{tabular}{lcc}
\hline Dados & Plano inclinado $(\mathrm{n}=92)$ & Equilíbrio térmico $(\mathrm{n}=68)$ \\
\hline Média & 4,7 & 5,2 \\
\hline Desvio Padrão & 1,7 & 1,5 \\
\hline Mediana & 4,7 & 5,4 \\
\hline Nota mínima & 1,25 & 2,0 \\
\hline Nota máxima & 8,0 & 8,0 \\
\hline Primeiro quartil & 3,5 & 4,1 \\
\hline Terceiro quartil & 6,0 & 6,3 \\
\hline
\end{tabular}

Para o questionário sobre o plano inclinado, a média foi de $59 \%$, a nota que mais se repetiu foi 4,0 e a metade das notas ficou entre $44 \%$ e $75 \%$. No questionário sobre equilíbrio térmico, a média foi de $65 \%$, as notas que mais se repetiram foram 3,0 e 6,0 e 
metade das notas ficou entre $51 \%$ e $79 \%$.

Ao longo do ano letivo, foram aplicadas três provas trimestrais no valor de doze pontos cada. As notas obtidas por cada aluno foram somadas e transformadas em percentual, valor que, de agora em diante, é denominado apenas como Trimestral. Os resultados dos alunos participantes da pesquisa estão na Tabela 2.

Tabela 2. Resultados Trimestrais $(\mathrm{n}=160)$

\begin{tabular}{lc}
\hline Dados & Valor \\
\hline Média & 59,4 \\
\hline Desvio Padrão & 16,8 \\
\hline Mediana & 57,8 \\
\hline Nota mínima & 16,8 \\
\hline Nota máxima & 96,1 \\
\hline Correlação - Questionário plano inclinado & 0,72 \\
\hline Correlação - Questionário equilíbrio térmico & 0,66 \\
\hline
\end{tabular}

Na Tabela 2, há ainda as correlações entre as notas dos alunos na Trimestral e nos questionários específicos. Os valores obtidos, ambos com significância menor que 0,01 são satisfatórios, corroborando a consideração de que os resultados obtidos na Trimestral e nos questionários estão relacionados e, supostamente, são frutos do conhecimento conceitual do estudante.

\section{Desempenho experimental na investigação}

Conforme informado anteriormente, ao finalizar a atividade investigativa, cada dupla tinha o histórico da investigação gravado em um arquivo. As Figuras 6 e 8 trazem exemplos desses históricos e de como as informações foram arquivados. É possível verificar que todos os dados fornecidos para as variáveis, além das justificativas, previsões e comentários sobre os resultados foram salvos, nos permitindo analisar e avaliar o desempenho experimental da dupla durante a atividade. Por meio dos históricos, podemos saber, portanto, o número de experimentos realizados, as modificações experimentais feitas entre cada tomada de dados, se os alunos realizaram testes experimentais adequados e consistentes, as estratégias utilizadas e o porquê da realização de cada experimento, aspectos fundamentais que caracterizam o desempenho experimental.

A análise dos históricos das duplas também permitiu a classificação da qualidade da investigação realizada. As categorias definidas na Figura 7 dizem respeito, sobretudo, à exploração do campo experimental e à utilização de testes experimentais adequados e consistentes $^{1}$. Tal categorização se mostrou eficiente em Gomes, Borges e Justi (2008a) para evidenciar a relação entre o desempenho experimental e a compreensão do objetivo da atividade.

1 Nas Figuras 6 e 8 encontram-se investigações classificadas como Fraca e Muito Boa, respectivamente, de acordo com a categorização proposta. 


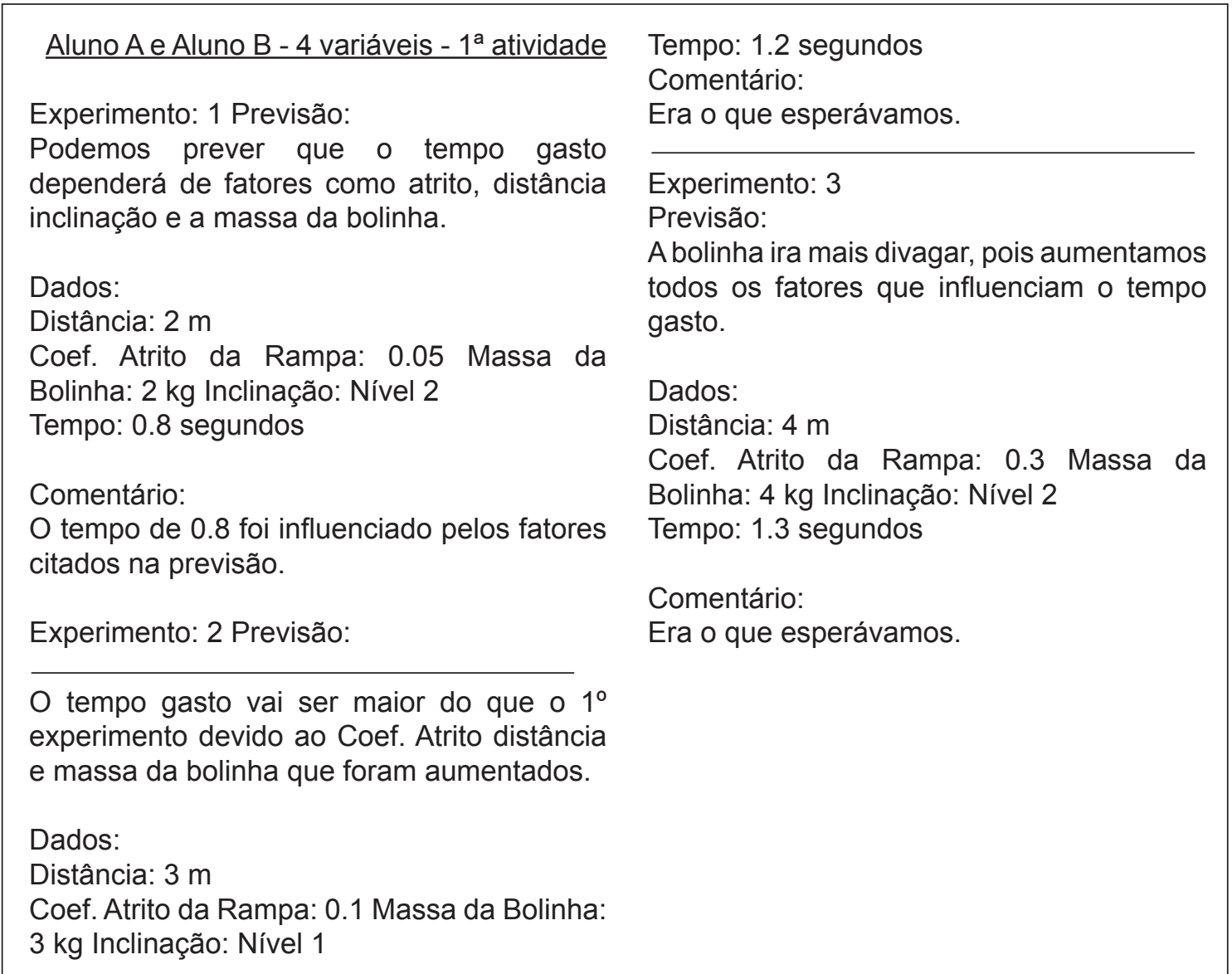

Figura 6. Exemplo de histórico de investigação

\begin{tabular}{|l|l|}
\hline Categorias & Descrição \\
\hline Muito Boa & $\begin{array}{l}\text { Quando a dupla realizou pelo menos um teste experimental adequado e consistente } \\
\text { para todas as variáveis independentes. }\end{array}$ \\
\hline Boa & $\begin{array}{l}\text { Quando a dupla realizou pelo menos um teste experimental adequado e consistente } \\
\text { para pelo menos 50\% das variáveis independentes. }\end{array}$ \\
\hline Fraca & $\begin{array}{l}\text { Quando a dupla realizou a maioria dos testes experimentais de forma inconsistente } \\
\text { e explorou a influência de poucas variáveis independente. }\end{array}$ \\
\hline
\end{tabular}

Figura 7. Categorias utilizadas para classificação das investigações realizadas 
Aluno $X$ e Aluno $Y-4$ variáveis - $1^{\mathrm{a}}$ atividade

Experimento1

Previsão: Colocamos 0.30 de atrito da rampa, 4 $\mathrm{kg}$ da massa da bolinha, 4 metros a distância e a inclinação da rampa normal. Nós esperamos que a massa da bolinha aumente a velocidade do corpo, porém o atrito irá freá-lo, o que vai influenciar no tempo gasto pela bolinha. Quanto maior a distância, maior deverá ser a velocidade da bolinha e quanto maior a inclinação, maior a aceleração da bolinha.

Dados:

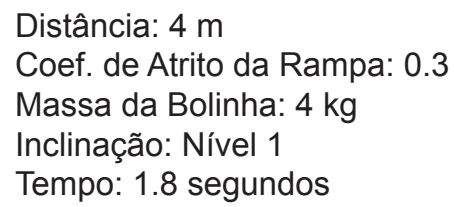

Comentário: Nós esperávamos que o tempo seria maior, devido ao atrito e a inclinação por não ser a máxima. O tempo gasto foi 1.8 segundos.

Experimento 2

Previsão: Alteramos nessa segunda simulação a inclinação da rampa que passou a ser a muito inclinada. Os outros dados continuaram os mesmos. Nós esperamos que o tempo seja menor, pois acreditamos que a aceleração será maior.

Dados:

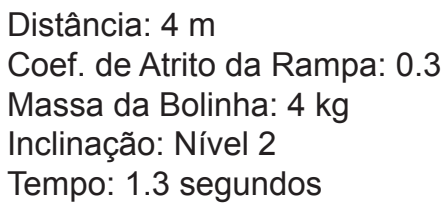

Comentário: Ocorreu o previsto e isso comprova que quanto maior a inclinação, maior a aceleração do sistema, logo o tempo será menor.

Experimento 3

Previsão: Nós esperamos que nessa terceira previsão o tempo gasto seja menor, pois o atrito foi reduzido e o atrito tem a função de "frear" o sistema.

Dados:

\author{
Distância: 4 m \\ Coef. de Atrito da Rampa: 0.05 \\ Massa da Bolinha: $4 \mathrm{~kg}$ \\ Inclinação: Nível 1 \\ Tempo: 1.4 segundos
}

Comentário: O resultado foi o esperado, o tempo foi menor, pois o tempo em nossa primeira observação foi de $1.8 \mathrm{~s}$ enquanto agora foi de 1.4 .

\section{Experimento 4}

Previsão:Nessa quarta observação, esperamos que o tempo seja menor, pois a distância percorrida será menor do que da primeira observação.

Dados:

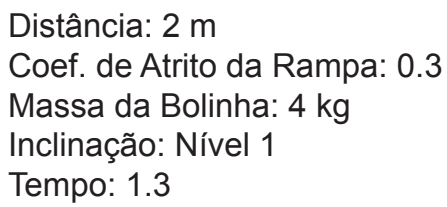

Comentário: O resultado foi o esperado, pois o tempo gasto foi menor (1.3s) em relação a nossa primeira observação (1.8s).

\section{Experimento 5}

Previsão:Esperamos nessa quinta observação que o tempo seja maior, pois diminuímos a massa da bolinha para $2 \mathrm{~kg}$.

Dados:

Distância: $4 \mathrm{~m}$ Coef. de Atrito da Rampa: 0.3 Massa da Bolinha: $2 \mathrm{~kg}$ Inclinação: Nível 1 Tempo: 1.8 segundos

Comentário:O resultado não foi esperado pois o tempo gastos em ambos foi igual (1.8s). Isso comprova que a massa não influência no tempo.

Figura 8. Exemplo de histórico de investigação

\section{Resultados e discussão}

Para identificar a relação entre o conhecimento conceitual dos estudantes e seu desempenho durante a atividade investigativa foi necessário analisar a composição de cada uma das 80 duplas participantes da pesquisa. Foram selecionadas apenas aquelas nas quais os dois alunos obtiveram notas acima (formando o grupo de rendimento superior, chamado de Grupo 1) e abaixo da média (formando o grupo de rendimento inferior, 
chamado de Grupo 2) no questionário². O total de duplas selecionadas, segundo esse critério, bem como o número de duplas por configuração experimental é apresentado na Tabela 3.

Tabela 3. Número de duplas selecionadas segundo o resultado do questionário

\begin{tabular}{|c|c|c|c|c|}
\hline \multirow[b]{2}{*}{ Tema } & \multirow[b]{2}{*}{$\begin{array}{c}\text { Variáveis } \\
\text { independentes }\end{array}$} & \multicolumn{2}{|c|}{ Grupos de rendimento no questionário } & \multirow[b]{2}{*}{ Totais } \\
\hline & & $\begin{array}{c}\text { Grupo } 2 \\
\text { (Desempenho Inferior) }\end{array}$ & $\begin{array}{c}\text { Grupo } 1 \\
\text { (Desempenho Superior) } \\
\end{array}$ & \\
\hline \multirow{2}{*}{$\begin{array}{l}\text { Plano } \\
\text { inclinado }\end{array}$} & 2 & 6 & 4 & \multirow{2}{*}{27} \\
\hline & 4 & 9 & 8 & \\
\hline \multirow{2}{*}{ Temperatura } & 2 & 3 & 5 & \multirow{2}{*}{17} \\
\hline & 4 & 3 & 6 & \\
\hline Totais & & 21 & 23 & 44 \\
\hline
\end{tabular}

Levando-se em consideração as notas da Trimestral, foram identificadas 40 duplas que atendiam ao mesmo critério. Dessas, 28 também foram selecionadas devido às notas no Questionário. As informações da Tabela 4 enfatizam a relação entre os resultados das duas fontes de dados. Das 28 duplas, 25 pertencem ao mesmo grupo. Esse resultado é mais um indício da existência de uma relação significativa entre o rendimento dos alunos na Trimestral e no Questionário $(\chi 2(1)=17,3, \mathrm{p}<0,001)$, fato que reforça a consideração da nota no Questionário como um reflexo do conhecimento conceitual do aluno sobre o tema da investigação.

Tabela 4. Relação dos rendimentos das duplas na Trimestral e questionários

\begin{tabular}{lccc}
\hline \multirow{2}{*}{$\begin{array}{l}\text { Grupos de rendimento } \\
\text { na Trimestral }\end{array}$} & \multicolumn{2}{c}{ Rendimento no Questionário } & Grupo 1 \\
\cline { 2 - 4 } & Grupo 2 & Totais \\
Inferior & 12 & 2 & 14 \\
\hline Superior & 1 & 13 & 14 \\
\hline Totais & 13 & 15 & 28 \\
\hline
\end{tabular}

Ao avaliarmos os aspectos relacionados ao desempenho experimental das duplas como o número de experimentos realizados, a porcentagem de testes adequados e consistentes e a qualidade geral da investigação e compararmos os resultados entre os grupos de desempenho superior (Grupo 1) e inferior (Grupo 2), poderemos identificar se o conhecimento conceitual do estudante influencia no desempenho durante a realização da investigação.

O primeiro item de análise diz respeito ao número de experimentos realizados. $\mathrm{Na}$ Tabela 5 são apresentadas as médias de experimentos realizados por dupla, de acordo com a configuração experimental e o grupo de rendimento no Questionário.

2 Foram consideradas as notas dos alunos apenas no questionário do mesmo tema da atividade investigativa realizada. Portanto, para efeito de terminologia, será utilizado o termo Questionário no singular desse ponto em diante do trabalho quando necessário. 
Tabela 5. Média de experimentos realizados

\begin{tabular}{|c|c|c|c|}
\hline \multirow{3}{*}{ Tema } & \multirow{3}{*}{$\begin{array}{c}\text { Variáveis } \\
\text { independentes }\end{array}$} & \multicolumn{2}{|c|}{ Média de experimentos realizados } \\
\hline & & Grupo 2 & Grupo 1 \\
\hline & & (Desempenho Inferior) & (Desempenho Superior) \\
\hline \multirow{2}{*}{ Plano inclinado } & 2 & 5,8 & 4,8 \\
\hline & 4 & 5,3 & 7,4 \\
\hline \multirow{2}{*}{ Temperatura } & 2 & 3,3 & 3,6 \\
\hline & 4 & 6,0 & 5,8 \\
\hline
\end{tabular}

Comparando-se as médias de experimentos realizados entre os grupos 1 e 2, percebe-se que não há uma tendência ou uma relação evidente, nem mesmo quanto ao número de variáveis. Assim, o número de experimentos realizados não é um parâmetro do desempenho dos estudantes influenciado pelo conhecimento conceitual. Nem sempre a realização de um número relativamente grande de experimentos significa, necessariamente, que o campo experimental foi devidamente explorado (como testar todas as variáveis independentes, por exemplo), ou que os experimentos realizados produziram evidências confiáveis.

Para cada dupla, foi calculada a proporção de testes adequados e consistentes feitos. Os valores são exibidos na tabela 6. Para este cálculo, dividiu-se o número de experimentos classificados como adequados e consistentes pelo número de experimentos realizados menos um. Isso porque, para se classificar um teste experimental como adequado e consistente, deve-se contrastá-lo com algum experimento anterior (Schwichow et al., 2016). Como no primeiro experimento não há como efetuar essa comparação, não se pode incluí-lo no cálculo.

Tabela 6. Proporção de experimentos adequados e consistentes realizados

\begin{tabular}{|c|c|c|c|}
\hline \multirow{3}{*}{ Tema } & \multirow{3}{*}{$\begin{array}{c}\text { Variáveis } \\
\text { independentes }\end{array}$} & \multicolumn{2}{|c|}{ Média de experimentos adequados e consistentes } \\
\hline & & Grupo 2 & Grupo 1 \\
\hline & & (Desempenho Inferior) & (Desempenho Superior) \\
\hline \multirow{2}{*}{$\begin{array}{l}\text { Plano } \\
\text { inclinado }\end{array}$} & 2 & 0,8 & 1,0 \\
\hline & 4 & 0,2 & 0,7 \\
\hline \multirow{2}{*}{ Temperatura } & 2 & 0.7 & 0,9 \\
\hline & 4 & 0,5 & 0,6 \\
\hline
\end{tabular}

O que se percebe nos dados da tabela 6 é a influência do número de variáveis da situação-problema sobre a proporção de experimentos adequados e consistentes. Considerando o mesmo tema e grupo de rendimento, as duplas que executaram a atividade com duas variáveis obtiveram proporções de experimentos adequados e consistentes superiores às das duplas que realizaram a investigação com quatro variáveis 
$(\mathrm{H}(1)=16,6, \mathrm{p}<0,01)^{3}$. Pode-se concluir, então, que a quantidade de variáveis envolvidas na investigação afeta a capacidade dos alunos de realizar um controle de variáveis efetivo. Esse resultado é, de certa forma, esperado e plenamente justificável. Com o aumento do número de variáveis independentes na atividade, a dificuldade de realizar um teste adequado e consistente aumenta, pois o número de variáveis a serem manipuladas é maior.

Outra inferência possível de ser extraída dos dados da Tabela 6 é a de que, em todas as configurações experimentais, o Grupo 1 obteve médias superiores às do Grupo 2. No geral, essa diferença é significativa: $\mathrm{H}(1)=4,8, \mathrm{p}=0,03$, sendo que a diferença mais acentuada ocorreu na atividade do plano inclinado com quatro variáveis independentes.

Para obtermos mais indícios da influência do conhecimento conceitual dos estudantes sobre suas estratégias na execução da atividade, utilizamos a classificação da qualidade da investigação realizada por cada dupla de acordo com as categorias presentes na Figura 7. Na Tabela 7, visualizamos o número total de duplas distribuídas de acordo com a categorização proposta e os grupos de desempenho no questionário. Apesar da diferença entre os grupos não ser estatisticamente significativa $(\chi 2(2)=2,3$, $\mathrm{p}=0,32)$, pode-se verificar que as investigações de pouco mais da metade das duplas do Grupo 1 foram classificadas como Muito Boa, enquanto a maioria das duplas do Grupo 2 teve sua investigação classificada como Fraca ou Boa. Da mesma forma, há um predomínio no número de duplas de rendimento superior nas categorias Boa e Muito Boa, enquanto as duplas de rendimento inferior foram maioria na categoria Fraca.

Tabela 7. Qualidade de execução da atividade e desempenho no Questionário

\begin{tabular}{lccc}
\hline & \multicolumn{2}{c}{ Grupos de desempenho no questionário } & Totais \\
\cline { 2 - 4 } Categorias & Grupo 2 & Grupo 1 & 14 \\
\hline Fraca & 9 & 5 & 10 \\
\hline Boa & 4 & 6 & 20 \\
\hline Muito Boa & 8 & 12 & 44 \\
\hline Totais & 21 & 23 & 12 \\
\hline
\end{tabular}

Se considerarmos as duas atividades realizadas com quatro variáveis independentes, tem-se que, das doze investigações realizadas pelas duplas do Grupo 2, oito foram classificadas como Fraca e duas como Muito Boa, ao passo que, das 14 investigações feitas por duplas do Grupo 1, seis foram classificadas como Muito Boa e cinco como Fraca.

A análise dos históricos também nos permitiu identificar que uma diferença marcante entre as duplas que tiveram suas investigações classificadas como Muito Boa em relação àquelas cujas investigações foram categorizadas como Fraca foi a iniciativa

3 Foi utilizado o teste de Kruskal-Wallis, pois, diferentemente da ANOVA, esse teste não requer uma distribuição normal da variável independente para cada valor dos fatores considerados. 
e a capacidade de organizar os dados, registrando os valores atribuídos às variáveis independentes e anotando os resultados parciais durante a resolução do problema prático, uma vez que o software de simulação reiniciava os valores a cada experimento. Isso demonstra certa maturidade e regulação do raciocínio, além de uma reflexão em ação durante a execução, que podem contribuir de forma decisiva na qualidade da atividade realizada (Dedić, 2014). Esse fato pode ser verificado no histórico apresentado na Figura 6, no qual a dupla de alunos comparou os demais experimentos sempre com o resultado do primeiro experimento. Como exemplo, transcrevemos abaixo as previsões e os comentários feitos por outra dupla, pertencente ao grupo de rendimento superior no Questionário, e que também teve sua investigação categorizada como Muito Boa.

Previsão do experimento $\mathrm{N}^{\circ} 1$ (P1): Não há muito que esperar já que é o primeiro experimento.

Comentário sobre o resultado do experimento №1 (C1): Agora temos um primeiro valor iremos variar as grandezas para verificar o que influenciará ou não nos resultados.

P2: Variaremos o atrito e deixaremos as outras grandezas constantes para ver se ele irá mudar o resultado. Nós esperamos que o tempo aumente.

C2: O tempo aumentou como o esperado. Podemos então concluir que o atrito influencia no tempo.

P3: Iremos variar a massa da bolinha para ver se isso mudará o tempo. Esperamos que o tempo não mude em relação ao $1^{\circ}$ experimento.

C3: O resultado foi o esperado. A massa da bolinha não influencia porque a força da gravidade é a mesma para qualquer massa.

P4: Variamos a distância para ver se ela influenciará no tempo. Esperamos que sim, pois quanto maior a distância maior o tempo para percorrê-la.

C4: O resultado foi como o esperado. O tempo varia com a distância.

P5: Diminuiremos a inclinação para ver se ela influenciará no resultado. Esperamos que sim, esperamos que o tempo seja maior que na primeira experiência.

C5: Foi o que aconteceu. Como a inclinação diminui, a velocidade diminui e o tempo aumenta.

No trecho transcrito, a dupla menciona o resultado do primeiro experimento e, ainda, é possível observar referências explícitas ao controle de variáveis. Isso pode ser verificado apenas em alguns outros históricos de investigações, todas classificadas como Muito Boa.

Por sua vez, nos históricos das investigações categorizadas como Fraca, foi possível identificar que os alunos não consideraram o objetivo proposto para a atividade, mas sim objetivos mais práticos como, por exemplo, configurar o sistema de tal forma 
que a esfera percorra a rampa no maior/menor tempo possível ou configurá-lo de modo a permitir a maior/menor temperatura de equilíbrio térmico.

No trecho a seguir, estão transcritos a última previsão e o último comentário de uma dupla que realizou 10 experimentos, dos quais apenas 3 podem ser classificados como adequados e consistentes ao trabalhar a investigação do plano inclinado com quatro variáveis:

P10: Esperamos que faça o percurso mais demorado possível.

C10: Foi o maior tempo feito nos últimos experimentos, já que diminuímos o valor das variáveis que aumentam a velocidade e aumentamos o valor das variáveis que diminuem $o$ valor da velocidade.

A distorção e/ou a má compreensão dos objetivos da atividade já foram identificadas na literatura da área e são consideradas uma das razões para o desempenho abaixo do esperado de alguns estudantes em investigações (Bybee, 2011; Hart et al., 2000).

Foi possível verificar, ainda, que muitas duplas de estudantes mudaram de estratégia durante a investigação. Algumas iniciaram executando testes experimentais adequados e consistentes e passaram a realizar experimentos inconsistentes e controversos. Outras duplas agiram de maneira oposta. Ao todo, dos $198^{4}$ testes experimentais realizados, cerca de $70 \%$ puderam ser considerados adequados e consistentes e visavam determinar o efeito de apenas uma variável, enquanto as demais variáveis eram mantidas constantes. Essas mudanças de estratégias deixam claro que a habilidade de controlar variáveis para essas duplas ainda é problemática e limitada a situações restritas. Isto corrobora pesquisas que indicam que as estratégias se desenvolvem e se modificam lentamente ao longo da resolução do problema, que indivíduos não possuem apenas uma forma de pensar sobre uma determinada classe de problemas e que a mudança da estratégia não é repentina, isto é, estratégias adequadas e inadequadas podem coexistir ao longo das atividades (Schauble, 1990; Siegler, 1999).

\section{Considerações Finais}

O programa de pesquisa no qual este trabalho se insere tem por objetivo discutir as aprendizagens que podem resultar a partir da resolução de atividades investigativas em graus variados de abertura e especificação em um ambiente de aprendizagem implementado no ambiente escolar, criado especialmente para deslocar o centro da atenção do aluno da manipulação de equipamentos e da medição para a reflexão sobre suas ações.

Com este trabalho em específico, almejávamos responder às seguintes questões de pesquisa:

- Como se manifesta a influência do conhecimento conceitual do estudante sobre o seu

4 Esse número foi obtido somando-se todos os testes experimentais realizados por cada dupla, menos o primeiro teste. 
desempenho durante a realização de uma atividade investigativa?

- Como as estratégias experimentais utilizadas pelos estudantes permitem relacionar o seu conhecimento conceitual com o desempenho na realização da investigação?

Nossos resultados apontam que o número de experimentos realizados não se configura como um parâmetro do conhecimento procedimental influenciado pelo conhecimento conceitual, pois a quantidade de experimentos não está diretamente relacionada à exploração do campo experimental, nem com a produção de evidências válidas.

A complexidade da investigação, medida pelo número de variáveis independentes, é um fator que influencia no desempenho dos estudantes, sobretudo na capacidade de realizar testes adequados e consistentes, fato também verificado em pesquisas anteriores (Klahr, 2000; Schauble, 1996). Identificamos ainda que, em geral, a influência do aumento da complexidade da atividade foi maior no grupo de desempenho inferior (Grupo 2) e que este grupo apresentou médias inferiores em relação ao grupo de desempenho superior (Grupo 1) em todas as configurações das situações-problema.

Com relação à qualidade da investigação realizada, pudemos verificar que a maioria das investigações classificadas como Muito Boa são de duplas pertencentes ao Grupo 1 e se considerarmos apenas as atividades com quatro variáveis, a diferença entre os grupos de desempenho é mais acentuada.

A análise dos históricos das duplas nos possibilitou caracterizar as estratégias utilizadas por elas durante o processo de resolução do problema prático. Foi possível identificar que as investigações categorizadas como Muito Boa (maioria pertencentes ao Grupo 1) apresentaram uma maior capacidade de organização e de regulação ao executar a atividade, o que parece ter contribuído para a execução de uma investigação mais eficiente.

Os resultados desse trabalho, juntamente com pesquisas anteriores, fornecem indícios de que alunos que apresentam um maior conhecimento conceitual apresentam também estratégias mais adequadas e sofisticadas de controle de variáveis e de experimentação (Bogdan, 2016; Borges, Borges, \& Vaz, 2005; Edelsbrunner et al., 2016). O entendimento conceitual pertinente ao problema seria, assim, um fator importante para estruturar e alcançar uma solução satisfatória para problemas práticos. Ao fazerem uso de seu conhecimento conceitual para entender melhor as situações propostas e formular hipóteses mais consistentes sobre o fenômeno, os alunos conseguem, mais facilmente, empregar e regular a utilização de testes experimentais adequados e consistentes e analisar melhor as evidências disponíveis. Tal conclusão pode, talvez, ser explicada de maneira inversa: os alunos que possuem um modelo adequado de causalidade entre variáveis, dominam estratégias adequadas de controle de variáveis e executam atividades de forma mais organizada têm maiores possibilidades de compreender sistemas multicausais e problemas relacionados às Ciências e Matemática, apresentando, assim, melhores rendimentos escolares. Dessa forma, o aumento na 
sofisticação do pensamento científico, quer em crianças ou em adolescentes, envolve a mudança de estratégia e o desenvolvimento do conhecimento. Isso corrobora a visão de Schauble (1996, p.118) de que

o raciocínio adequado dá suporte à escolha de uma estratégia apropriada de investigação e a estratégia de investigação válida e sistemática dá suporte ao desenvolvimento de um conhecimento mais apurado e complexo.

A execução de investigações em duplas parece ter sido decisiva para a realização da atividade. Ao trabalhar em duplas, cada aluno supre as demandas cognitivas do outro, e as discussões geradas contribuem para que eles explorem seus conhecimentos e estratégias, o que leva a um aumento do controle e da regulação dos procedimentos adotados.

O uso de simulações computacionais pode contribuir para a superação de muitas das dificuldades relacionadas com o ensino e aplicação dos conceitos básicos de Ciências, fornecendo um ambiente que possibilite aos estudantes a modelagem de suas ideias e o aumento da compreensão do sistema modelado. Acreditamos, assim como Sousa, Malheiros e Figueiredo (2013) que a capacidade que as simulações possuem de representar e permitir aos estudantes explorar o comportamento dinâmico do sistema cria uma oportunidade única para ajudá-los a testar hipóteses e produzir explicações mais sofisticadas para o fenômeno em questão.

Como implicações educacionais do nosso estudo, defendemos que não se pode esperar dos estudantes um bom entendimento sobre as questões que envolvem o controle de variáveis, a execução de testes experimentais adequados e consistentes e a sua generalização para quaisquer fenômenos ou problemas se não forem dadas a eles oportunidades de aprendê-las e praticá-las. Um possível caminho talvez seja a elaboração de investigações específicas que estimulem os estudantes a utilizar tais estratégias. Essas atividades, além de bem orientadas, devem ter uma grande participação dos estudantes para que estes executem e reconheçam a importância do controle de variáveis na interpretação dos resultados, revisão de suas hipóteses iniciais e na mudança de suas concepções sobre o efeito de cada variável envolvida (Kuhn, 2016). Espera-se que, com a realização de uma sequência de investigações de variados graus de abertura e especificação, os estudantes sejam capazes de resolver problemas progressivamente mais complexos, numa gama maior de contextos e domínios e, ao mesmo tempo, de desenvolver estratégias de experimentação mais adequadas. Nesse caso específico, nossos resultados sugerem que a sequenciação das atividades deve partir daquelas envolvendo contextos mais familiares, mais estruturadas, com poucas variáveis e progressivamente introduzir atividades mais complexas, com maior número de variáveis e mais abertas. É preciso, antes de tudo, propiciar tempo para que os estudantes reconstruam seu entendimento sobre o aprender Ciências e sobre o papel da experimentação.

Nosso trabalho sinaliza, ainda, algumas questões em aberto para a pesquisa na área: como os alunos revisam e modificam suas ações e estratégias durante a atividade? Como eles rejeitam estratégias e procedimentos antigos em detrimento a novos? As 
respostas a essas perguntas exigiriam um acompanhamento mais individualizado do trabalho de cada dupla e uma análise mais detalhada de todo o processo de investigação.

Finalmente, se pretendemos incorporar as atividades investigativas ao ensino de Física e de Ciências, como forma de promover uma aprendizagem mais efetiva, acreditamos ser necessário empregar grande esforço para compreender a interação entre os conhecimentos conceitual e procedimental dos estudantes, assim como suas modificações e evoluções durante as investigações. A nosso ver, isso é fundamental para que sejam estabelecidas metas curriculares visando promover o desenvolvimento do pensamento científico dos nossos alunos.

\section{Referências}

Alexander, P. A., \& Judy, J. E. (1988). The interaction of domain-specific and strategic knowledge in academic performance. Review of Educational Research, 58(4), 375-404. https://doi.org/10.3102/00346543058004375

Amsel, E., \& Brock, S. (1996). The development of evidence evaluation skills. Cognitive Development, 11(4), 523-550. https://doi.org/10.1016/S0885-2014(96)90016-7

Bassoli, F. (2014). Atividades práticas e o ensino-aprendizagem de ciência(s): mitos, tendências e distorções. Ciência \& Educação, 20(3), 579-593. https://doi. org/10.1590/1516-73132014000300005

Bogdan, A. M. (2016). Student reasoning from data tables: data interpretation in light of student ability and prior belief. (Doctoral thesis). The Ohio State University.

Borges, A. T. (2002). Novos rumos para o laboratório escolar de ciências. Caderno Catarinense de Ensino de Física, 19(3), 291-313.

Borges, O. N., Borges, A. T., \& Vaz, A. M. (2005). Os planos dos estudantes para resolver problemas práticos. Revista Brasileira de Ensino de Física, 27(3), 435-446. https://doi. org/10.1590/S1806-11172005000300022

Bybee, R. W. (2011). Scientific and engineering practices in K-2 classrooms. Science Teacher, 78(9), 34-40.

Carey, S. (2000). Science education as conceptual change. Journalof Applied Developmental Psychology, 21(1), 13-19. https://doi.org/10.1016/S0193-3973(99)00046-5

Carvalho, A. M. P. (2013). Ensino de Ciências por Investigação. 1. ed. São Paulo: Cengage Learning.

Chen, Z., \& Klahr, D. (1999). All other things being equal: Acquisition and transfer of the control of variables strategy. Child Development, 70(5), 1098-1120. https://doi. org/10.1111/1467-8624.00081 
Chi, M. T. H. (2008). Three types of conceptual change: Belief revision, mental model transformation, and categorical shift. In S. Vosniadou (Ed.). Handbook of Research on Conceptual Change (pp. 61-82). Hillsdale, NJ: Erlbaum.

Croker, S., \& Buchanan, H. (2011). Scientific reasoning in a real world context: The effect of prior belief and outcome on children's hypothesis testing strategies. British Journal of Developmental Psychology, 29(3), 409-424. https://doi.org/10.1348/026151010X496906

Deboer, G.E. (2006). Historical perspectives on inquiry teaching in schools. In L. B. Flick, \& N. G. Lederman (Eds.). Scientific inquiry and nature of science: Implications for teaching, learning, and teacher education. Dordrecht, The Netherlands: Springer, p. 17-35.

Dedić, Z. R. (2014). Metacognitive knowledge in relation to inquiry skills and knowledge acquisition within a computer-supported inquiry learning environment. Psychological Topics, 23(1), 115-141.

Driver, R., Squires, A., Rushworth, P., \& Robinson, V. W. (1994). Making sense of secondary science: research into children's ideas. London: Routledge.

Dunbar K. N., \& Klahr, D. (2012). Scientific thinking and reasoning. In K. J. Holyoak, \& R. Morrison (Eds.), Cambridge Handbook of Thinking and Reasoning (pp. 701718). Cambridge, England: Cambridge University Press. https://doi.org/10.1093/ oxfordhb/9780199734689.013.0035

Edelsbrunner, P. A., Schalk, L., Schumacher, R., \& Stern, E. (2016). Variable control and conceptual change: A large-scale quantitative study in elementary school. Recuperado de $<$ http://osf.io/n6gev>.

Faria, A. F., \& Vaz, A. M. (2014) Pensamento científico em artigos publicados de 2010 a 2014 em periódicos de Ensino de Física. In: Atas do XV Encontro de Pesquisa em Ensino de Física. Maresias, São Paulo.

Frederiksen, J. R., White, B. Y., \& Gutwill, J. (1999). Dynamic mental models in learning science: The importance of constructing derivational linkages among models. Journal of Research in Science Teaching, 36(7), 806-836. https://doi.org/10.1002/(SICI)10982736(199909)36:7<806::AID-TEA5>3.0.CO;2-2

Gilbert, J. K., \& Boulter, C. (Eds). (2000). Developing models in science education. Dordrecht: Kluwer. https://doi.org/10.1007/978-94-010-0876-1

Gomes, A. D. T., Borges, A. T., \& Justi, R. (2008a). Students' performance in investigative activity and their understanding of activity aims. International Journal of Science Education, 30(1), 109-135. https://doi.org/10.1080/09500690701697520

Gomes, A. D., Borges, A. T., \& Justi, R. (2008b). Processos e conhecimentos envolvidos na realização de atividades práticas: revisão da literatura e implicações para a pesquisa. Investigações em Ensino de Ciências, 13(2), 187-207. 
Gonçalves, M. E. R., \& Carvalho, A. M. P. (1994). Conhecimento físico nas primeiras séries do $1^{\circ}$ grau: o problema do submarino. Cadernos de Pesquisa, 90, 72-80.

Gott, R., \& Roberts, R. (2008). Concepts of evidence and their role in open-ended practical investigations and scientific literacy: background to published papers. Durham, UK: The School of Education, Durham University.

Hart, C., Mulhall, P., Berry, A., Loughran, J., \& Gunstone, R. (2000). What is the purpose of this experiment? or can students learn something from doing experiments. Journal of Research in Science Teaching, 37(7), 655-675. https://doi.org/10.1002/10982736(200009)37:7<655::AID-TEA3>3.0.CO;2-E

Kanari, Z., \& Millar, R. (2004). Reasoning from data: How students collect and interpret data in science investigations. Journal of Research in Science Teaching, 41(7), 748-769. https://doi.org/10.1002/tea.20020

Kang, S., Scharmann, L.C., \& Noh, T. (2004). Reexamining the role of cognitive conflict in science concept learning. Research in Science Education, 34(1), 71-96. https://doi. org/10.1023/B:RISE.0000021001.77568.b3

Keselman, A. (2003). Supporting inquirylearning by promoting normative understanding of multivariable causality. Journal of Research in Science Teaching, 40(9), 898-921. https:// doi.org/10.1002/tea.10115

Klahr, D. (2000). Exploring science: The cognition and development of discovery process. Cambridge: MIT Press.

Klahr, D., Zimmerman, C., \& Jirout, J. (2011). Educational interventions to advance children's scientific thinking. Science, 333(6045), 971-975. https://doi.org/10.1126/ science. 1204528

Klayman, J., \& Ha, Y. (1987). Confirmation, disconfirmation, and information in hypothesis testing. Psychological Review, 94(2), 211-228. https://doi.org/10.1037/0033295X.94.2.211

Koslowiski, B. (1996). Theory and evidence: The development of scientific reasoning. Cambridge, Massachusetts: MIT Press.

Kuhn, D. (2016). What do young science students need to learn about variables? Science Education, 100(2), 392-403. https://doi.org/10.1002/sce.21207

Kuhn, D., Amsel, E., \& O'loughlin, M. (1988). The development of scientific thinking skills. San Diego, California: Academic Press.

MEC. (1999). Parâmetros Curriculares Nacionais: Ensino Médio. Brasília: MEC/ SEMTEC.

Millar, R. (2010). Practical work. In J. Osborne, \& J. Dillon. good practice in science teaching: What research has to say (pp. 108-134). Glasgow: Open University Press. 
Millar, R., \& Driver, R. Beyond Processes. Studies in Science Education, 14(1), 23-62. https://doi.org/10.1080/03057268708559938

Morris, B. J., Croker, S., Masnick, A., \& Zimmerman, C. The emergence of scientific reasoning. In Kloos, H., Morris, B.J. \& Amaral, J. L. (Eds.). Current topics in children's learning and cognition (pp. 61-82). InTech, Rijeka, Croatia.

Nascimento, R. D., \& Gomes, A. D. T. (2017). Análise da validade e da fidedignidade de um questionário para identificação do conhecimento conceitual sobre plano inclinado e aceleração. Amazônia: Revista de Educação em Ciências e Matemáticas, 13(26), 56-68. http://dx.doi.org/10.18542/amazrecm.v13i26.4284

National Research Council (2000). Inquiry and the national science education standards: A guide for teaching and learning. Washington: National Academy Press.

National Research Council (2012). A framework for $k$-12 science education: Practices, crosscutting concepts, and core ideas. Washington, DC: National Academies Press.

Osborne, J. (2014). Teaching scientific practices: Meeting the challenge of change. Journal of Science Teacher Education, 25(2), 177-196. https://doi.org/10.1007/s10972014-9384-1

Pedaste, M., Mäeots, M., Siiman, L. A., De Jong, T., Van Riesen, S. A., Kamp, E. T., ..., \& Tsourlidaki, E. (2015). Phases of inquiry-based learning: Definitions and the inquiry cycle. Educational Research Review, 14, 47-61. https://doi.org/10.1016/j.edurev.2015.02.003

Penha, S. P., Carvalho, A. M. P., \& Vianna, D. M. (2015). Laboratório didático investigativo e os objetivos da enculturação científica: análise do processo. Revista de Educação, Ciências e Matemática, 5(2), 6-23.

Penner, D. E., \& Klahr, D. (1996). The interaction of domain-specific knowledge and domain-general discovery strategies: A study with sinking objects. Child Development, 67(6), 2709-2727. https://doi.org/10.2307/1131748

Rhoton, J. (2010). (Ed.). Science education leadership: Best practices for the new century. NSTA Press.

Roberts, M. J., \& Newton, E. J. (2001). Understanding strategy selection. International Journal of Human-Computer Studies, 54(1), 137-154. https://doi.org/10.1006/ ijhc.2000.0434

Ross, J. A. (1888). Controlling variables: A meta-analysis of training studies. Review of Educational Research, 58(4), 405-437. https://doi.org/10.3102/00346543058004405

Roth, W. M. (1995). Authentic School Science. Dordrecht: Kluwer. https://doi. org/10.1007/978-94-011-0495-1

Sasseron, L. H., \& Carvalho, A. M. P. (2003). O conhecimento físico em uma perspectiva intercultural. In Atas do IV Encontro Nacional de Pesquisa em Educação em Ciências. Bauru, SP. 
Schauble, L. (1990) Belief revision in children: The role of prior knowledge and strategies for generating evidence. Journal of Experimental Child Psychology, 49(1), 31-57. https:// doi.org/10.1016/0022-0965(90)90048-D

Schauble, L. (1996). The development of scientific reasoning in knowledge-rich contexts. Developmental Psychology, 32(1), 102-119. https://doi.org/10.1037/0012-1649.32.1.102 Schwichow, M., Zimmerman, C., Croker, S., \& Härtig, H. (2016). What students learn from hands on activities. Journal of Research in Science Teaching, 53(7), 980-1002. https://doi.org/10.1002/tea.21320

Siegler, R. S. (1999). Strategic development. Trends in Cognitive Science, 11(3), 430-435. https://doi.org/10.1016/S1364-6613(99)01372-8

Silveira, F. L. (1993). Validação de testes de lápis e papel. In M. A. Moreira, \& F. L. Silveira. Instrumentos de Pesquisa em Ensino e Aprendizagem. Porto Alegre: EDIPUCRS.

Sodian, B., Zaitchik, D., \& Carey, S. (1991). Young children's differentiation of hypothetical beliefs from evidence. Child Development, 62(4), 753-766. https://doi. org/10.2307/1131175

Sophian, C. (1997). Beyond competence: The significance of performance for conceptual development. Cognitive Development, 12(3), 281-303. https://doi.org/10.1016/S08852014(97)90001-0

Sousa, J. M., Malheiros, A. P. S., \& Figueiredo, N. (2015). Desenvolvendo práticas investigativas no Ensino Médio: o uso de um Objeto de Aprendizagem no estudo da Força de Lorentz. Caderno Brasileiro de Ensino de Física, 32(3), 988-1006. https://doi. org/10.5007/2175-7941.2015v32n3p988

Tschirgi, J. E. (1980). Sensible reasoning: A hypothesis about hypotheses. Child Development, 51(1), 1-10. https://doi.org/10.2307/1129583

Wandersee, J. H., Mintzes, J. J., \& Novak, J. D. (1994). Research on alternative conceptions. In D. L., Gabel (Ed). Handbook of Research on Science Teaching and Learning (pp. 177210). New York: MacMillan.

Wellman, H. M., \& Gelman, S. A. (1992). Cognitive development: foundational theories of core domains. Annual Review of Psychology,43, 337-375. https://doi.org/10.1146/ annurev.ps.43.020192.002005

Zimmerman, C. (2007) The development of scientific thinking skills in elementary and middle school. Developmental Review, 27(2), 172-223. https://doi.org/10.1016/j. dr.2006.12.001 
Rafaela Dinali Nascimento

${ }^{0}$ http://orcid.org/0000-0002-1524-2753 Universidade Federal de São João del-Rei São João del-Rei, Brasil rafaeladinali@hotmail.com

Alessandro Damásio Trani Gomes

${ }^{\oplus}$ http://orcid.org/0000-0001-9095-5270 Universidade Federal de São João del-Rei Departamento de Ciências Naturais São João del-Rei, Brasil alessandrogomes@ufsj.edu.br

Submetido em 20 de Dezembro de 2017 Aceito em 24 de Abril de 2018 Publicado em 23 de Junho de 2018 